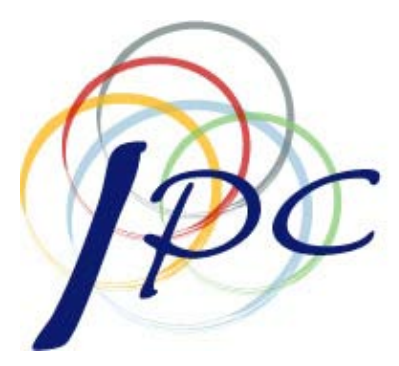

INTERNATIONAL Policy CENTER

Gerald R. Ford School of Public Policy University of Michigan

IPC Working Paper Series Number 98

\title{
Informal Payments and the Financing of Health Care in Developing and
} Transition Countries

Maureen Lewis

June 23, 2010 
Informal Payments and the Financing of Health Care in Developing and Transition Countries

Maureen Lewis

World Bank

Mlewis1@worldbank.org 


\begin{abstract}
Informal, under-the-table, payments to public health providers are increasingly being seen as a critically important source of health financing in developing and transition countries. With minimal funding levels and limited accountability publicly financed and delivered care falls prey to illegal payments, which require payments that can exceed 100 percent of median income. Methods to address the abuse include establishing official fees combined with improved oversight and accountability for public health providers, and a role for communities in holding providers accountable
\end{abstract}


Financing of health care in developing and transition countries takes many forms. Ironically it is the poorest countries that have the highest out of pocket expenditures as a percent of income. ${ }^{1}$ Government commitment to finance health care falls short in the lowest income countries for a number of reasons, the most obvious being modest tax revenues that limit spending on public health services leading to a gap between ideal investments and what can be afforded. A frequently overlooked factor is the low quality of public services and the related poor motivation of public servants ${ }^{2}$ that undermines public investments and compromises the value of the investments. Despite uneven spending by the public sector private spending is universal. A less apparent but important source of that private spending is under-the-table, or informal, payments by patients to public sector providers. Such payments make up a significant amount of spending in some countries and in most cases are illegal because all citizens are meant to receive free health care.

This paper provides an overview of the issue, the evidence on its frequency and cost to patients and a set of policy proposals for addressing informal payments and the underlying causes of their persistence.

Informal payments can be defined as "payments to individual and institutional providers, in kind or in cash, that are made outside official payment channels or are purchases meant to be covered by the health care system. This encompasses 'envelope' payments to physicians and 'contributions' to hospitals as well as the value of medical supplies purchased by patients and drugs obtained from private pharmacies but intended to be part of government-financed health care services." 3 Because informal payments are so often paid directly to individual providers they also fall into the category of using "public office for private gain" the accepted definition of corruption. ${ }^{4}$

Informal payments allow patients to jump the queue, receive better or more care, obtain drugs, or just simply receive any care at all. They allow those who can pay both access to health care and often higher quality care. But in addition to the undermining of equity, purportedly the rationale for subsidized health care, informal payments constitute institutionalized bribery, which taints the system as a whole. To some extent gratuity payments from appreciative patients are exceptions, but even in those cases there is evidence that such payments can serve as insurance against a future need for care, particularly from individual physicians.

While informal payments may be a form of corruption they are often symptomatic of bad management, a response to under-funding, a reflection of the absence of accountability or some combination of these. Whatever the source what emerges from the evidence is, surprisingly, how widespread informal payments are.

Like most informal activities informal payments go largely unreported. Information on the level and nature of informal payments can only be obtained from one or more of the following: observation, reports of other health providers, focus groups or, more commonly, reports from household surveys. 
The data reported here are taken from multiple sources: (1) household surveys with a heavy reliance on the World Bank's Living Standard Measurement Surveys (LSMS) but including other representative household surveys at local, province or national levels; (2) the World Bank sponsored corruption surveys that use a representative sample of officials, businessmen and citizens; (3) health facility exit surveys; (4) corruption studies by Transparency International; and (5) other representative surveys of irregular practices conducted in specific countries. Recall periods, an important source of potential bias in the data, vary depending on the survey with the most general being the corruption surveys that typically ask about experience in contact with the health care system over the past year. Others generally followed more standard periods of one to six months. Survey sources are provided in Appendix 1, where relevant data sources are not footnoted. ${ }^{5}$

A major challenge is differentiating among informal, payment official co-payment, bribes and gifts to providers as expressions of gratitude. Where all fees have been banned any payment by households is clearly unofficial, but in many countries formal fees exist alongside informal payments, blurring the dichotomy. It then becomes the level, the recipient and the timing of patient payment that become relevant in distinguishing the nature of the payment and its definition as gratituity or bribe.

Ex post financial transactions are particularly problematic in assessing informality of payment because post-service gratitude gestures are common and often expected. Where providers insist on direct pre-payment or receive direct payments for specific tasks (e.g., such as orderlies who require payment to move patients from room to room) or payments are not made to an official cash window, informality of payment is likely. For example, in Kyrgyz Republic in 200195 percent of those who paid for services did not receive a receipt while only 3 percent reported giving a gift to the health personnel at the time of service. ${ }^{6}$ A Bolivia study showed that perception of corruption was associated with the size of informal payment. ${ }^{7}$

Exhibit 1 summarizes the frequency of informal payments to public health care workers among users of health services. The frequency range is enormous from 3 percent in Peru to 96 percent in Pakistan. Regionally South Asia stands out for its heavy reliance on informal payments. East Asian experience is split between Thailand and Indonesia with low levels and the former Communist countries, with Cambodia at 55 percent and a dated estimate for Vietnam at 81 percent. The proportions for Latin America and Eastern Europe have a wide distribution with low levels in some countries and among the highest in others, making generalizations problematic. Recent evidence from smaller samples in Africa suggests that informal payments of various kinds are common in Uganda, Mozambique and Ethiopia. ${ }^{8}$ In all three, patients pay public providers directly for consultations and drugs over and above any formal charges.

Data sources vary with much of the information coming from either household surveys or national level governance and corruption studies. Some countries, like Bolivia (2002), Moldova, Kazakhstan (1999) and Poland (2002) used dedicated health facility exit surveys. ${ }^{9}$ Albania (2002), Bolivia (2001) and China data emanate from province level surveys, and the India data are from a district in Rajastan state. 


\section{Exhibit 1. Proportion who make Informal Payments Among Users of Health Services, Selected Countries}

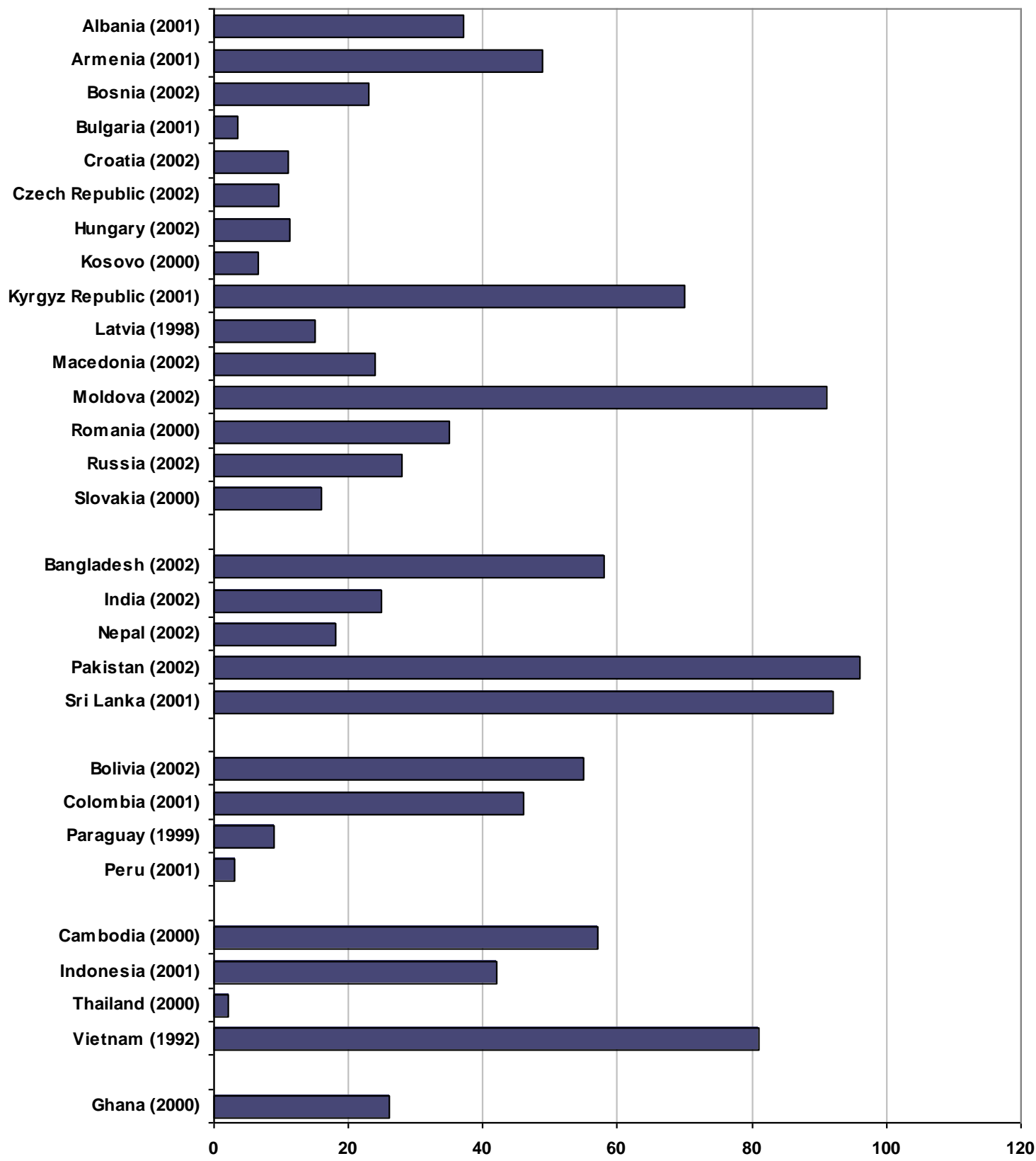


Where both large household surveys and smaller studies exist for the same country, the latter always show higher informal payments. Kazakhstan exhibits dramatically higher payments in the smaller hospital 2001 survey over a household survey in 2001. Albania's estimate of the frequency of informal payments in 1996 was 22 percent, but jumped to 28 and 60 percent, respectively, for outpatient and inpatient care in the smaller 2001 survey. Whether this is due to the greater attention to the issue with smaller, dedicated surveys, a focus on problematic areas or other factors, it suggests that some of the broader surveys underestimate the extent of patient payments.

Low levels of informal payments in Peru, Paraguay, Thailand and Kosovo may reflect the existence of and reliance on private sector alternatives that require significant out-ofpocket payments. Where consumers have more choice they should be better able to influence provider behavior. The higher rates reported for Colombia would question that explanation since Colombia has a large private health system not too different from Peru's. The differences may reflect different degrees of oversight in public clinics and hospitals, but that deserves additional attention.

Limited evidence of informal payment in the Czech Republic appears odd given the patterns observed elsewhere in Eastern Europe and Central Asia (ECA), but it is consistent with other findings regarding the Czech Republic as an outlier on this issue. Public providers with a quasi-monopoly position, as is the case in much of ECA where competition only exists across public providers, are in a stronger position to charge patients for their services. Rural areas or urban populations with limited access to alternative public or private services are particularly vulnerable to such practices as they are truly monopolistic providers.

Exhibit 2 shows differences in outpatient and inpatient payments. With the exception of Bulgaria, inpatient care is more likely to be financed via informal payments, and often the disparity between the two types of services is dramatic, as is the case with Bangladesh, Tajikistan, Armenia and Albania. Evidence for four representative Eastern European countries (Czech Republic, Hungary, Poland and Romania) reveals that formal payments are associated with primary and outpatient specialist care and informal payments with surgery and inpatient services. ${ }^{10}$ Households either feel the need to pay for hospitalizations or providers don't give them a choice, insisting on payment if services are to be rendered.

The perception surveys of providers or citizens while not statistically representative offer additional insights that quantitative surveys cannot capture. In Costa Rica 85 percent of medical staff indicated that under-the-table payments to physicians were common, and half of patients said they made payments in public facilities roughly equivalent to 50 percent of the cost ofr a private sector consultation. In Bolivia the incidence of informal payments was significantly correlated with perceptions of corruption in specific public hospitals, and 40 percent of interviewed patients acknowledged making illicit payments for care, this is similar to the results of a representative household survey in 106 Bolivian 


\section{Exhibit 2. Proportion of Patients Making Informal Payments by Type}

of Service, Selected Countries

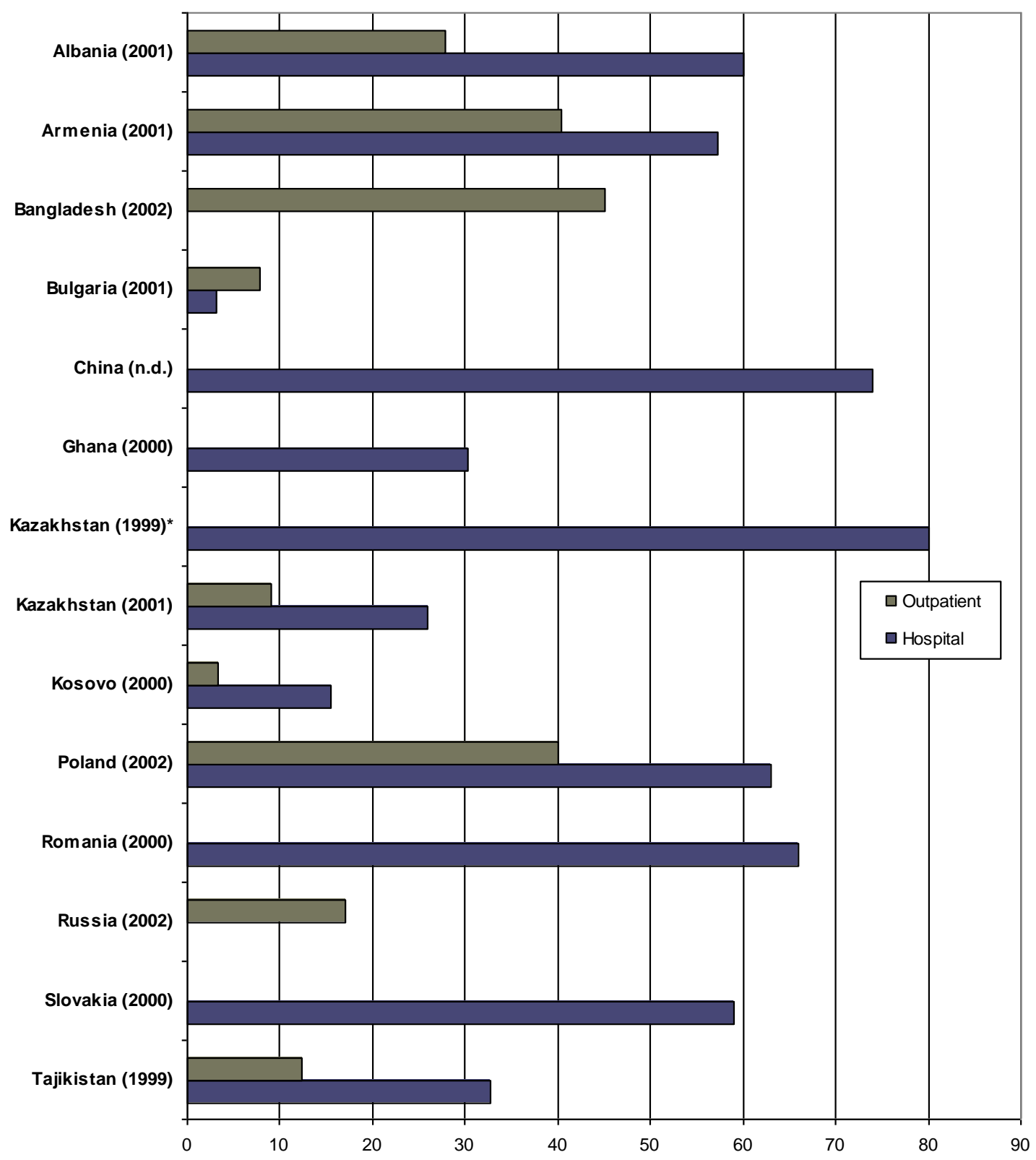


municipalities where 45 percent of patients reported paying informally. ${ }^{11}$ Interestingly, national surveys for Bolivia show that over 60 percent of those interviewed considered the health sector to be corrupt.

A comparative study of citizens in five South Asian countries (Bangladesh, India, Nepal, Pakistan and Sri Lanka) found that in all but Sri Lanka most payments were to meet ex ante demands from providers. Bribes are required in all five countries for admission to the hospital, to obtain a bed, and to receive subsidized medications. ${ }^{12}$ In Bangalore, India citizen feedback surveys revealed that informal payments were made to ensure proper treatment, but they were typically demanded by providers and 51 percent of those interviewed indicated they had paid bribes in government hospitals and 89 percent in hospitals in small cities, but they also paid informally in the private hospitals (24\%), suggesting a cultural norm of additional direct payment to providers. More dramatically, bribes were paid to nurses in maternity homes so mothers could see their infants. ${ }^{13}$

In Albania among the 60 percent of patients who received care 43 percent said the gift was requested. ${ }^{14}$ Using focus groups of patients and providers citizens explain the virtual market for publicly provided care in Poland. ${ }^{15}$ Informal payments have become the way to obtain the services of specific physicians, with pricing reflecting reputation and demand. It is an implicit form of insurance for possible future needs, and prices are commonly known. Thus the process of negotiation and payment for health services may be informal but it has evolved into a very sophisticated market in Poland.

The motivations of health staff and patients in relying on under the table payments are strong. Physicians argue that low pay, irregular salary payments, lack of government attention and the need to keep services going requires drastic action, and patient contributions offer the only source of funds to fill the gap. ${ }^{16}$ Patients on the other hand also see low pay as an impetus to contribute, but traditions of gratitude as well as concerns for some future need for health care also play a role.

Qualitative studies in Ethiopia with policymakers, experts and health workers revealed that inappropriate payments are rife in the health sector. Patients typically must pay for every service and each item, from hospital admittance to having a bed changed to drugs and supplies. ${ }^{17}$ Similar reports of itemized charging emerged from qualitative work in Albania, Georgia and Poland where the public system has become a fee-for service entity. ${ }^{18}$ Consumer confusion about the official or unofficial nature of payments is common. Patients pay but they don't always know why and they often do so at multiple locations or for different "services". ${ }^{19}$

Multivariate analysis sheds further light on some of the underlying motivations for informal payment as well as whether patient revenues are well spent. In Kazakhstan, an econometric analysis of patients discharged from three hospitals in Almaty City concluded that informal payments made in the admission department before treatment, and the amount paid subsequently at both admissions and hospital wards shortened admission time for surgery. ${ }^{20}$ The study found longer lengths of stay associated with payments to both the admissions department and directly to individual providers on the 
wards. Quality as perceived by patients increased with the amount paid informally. These results confirm the assumption that patients pay to receive more attentive and "higher quality" care as they perceive it. Longer lengths of stay do not necessarily mean better clinical care, but shorter waits, longer hospital stays and attentive treatment by medical staff tend to be valued by patients. In Kazakhstan paying ensures that health care meets the demands and perceived needs of patients.

Of concern is the relative cost of the services to patients, and numerous studies point out the impact on the poor. Exhibit 3 summarizes the available data showing the average cost of an outpatient visit or hospital admission as a percent of half monthly average income, roughly equivalent to median income. The level of inpatient payments far exceeds the amounts paid out for outpatient services and numerous studies document the extent of hardship some households face in meeting these costs. Inpatient costs can exceed annual family income forcing the sale of assets or the accumulation of debt in order to afford care. ${ }^{21}$ Selected studies in China of "red packages" paid to providers report that payments average between 140-320 yuan per hospital visit (US\$16-36), with referral hospitals averaging 400 yuan (US\$44), roughly 90 percent of half monthly income, suggesting the difficulty of affording health care. ${ }^{22}$

Two studies in Albania examined patient income and the size of informal payments. The analysis of a three province survey showed that rural residents were more likely to pay for services than were urban patients and they paid roughly the same fees as patients in other income brackets. So income had little effect on the probability of having to pay informally. ${ }^{23}$ Estimates from a national representative survey showed high inelastic demand in the face of small increases in the price of health services, indicating again that patients are not particularly price sensitive in Albania. ${ }^{24}$ As a result, informal payments are highly regressive.

Fee exemptions offer the potential for husbanding scarce resources for those least able to afford health care. Many systems have instituted such procedures to retain the benefits of co-payments without unduly burdening the poor. ${ }^{25}$ Evidence on effectiveness, however, suggests problems with the approach. In Bangladesh data from interviews and observations in a sample of four hospitals showed that 75 percent of the time the lowest income group paid the least amount both officially and unofficially. In the outlier institutions the poor paid more than the wealthiest group but the same as or less than middle income patients. Payments are also standardized and routinized with specific time periods for charging during inpatient stays rather than at discharge. ${ }^{26}$ In Rajasthan, India, patients regularly pay for "free" outpatient care, though the poorest patients pay 40 percent less than the highest income patients. It should be noted that in this part of India everyone is poor and poverty is relative, but on average 7.3 percent of total household spending goes to paying for health care. ${ }^{27}$ In Uganda exemptions were extended to the politically powerful and those overseeing the local health care program, a perverse version of exemption meant to ensure equal access but in this case subsidizing the better off. ${ }^{28}$ Central Asia's experience has not been encouraging either, with minimal exemptions for lower income patients. ${ }^{29}$ Evidence from Kazakhstan showed that for major illnesses the lowest income households spent more than twice their monthly 
Exhibit 3. Average Informal Payments as Percentage of Half-monthly Per Capita Income, Selected Countries (Int'I \$ PPP)

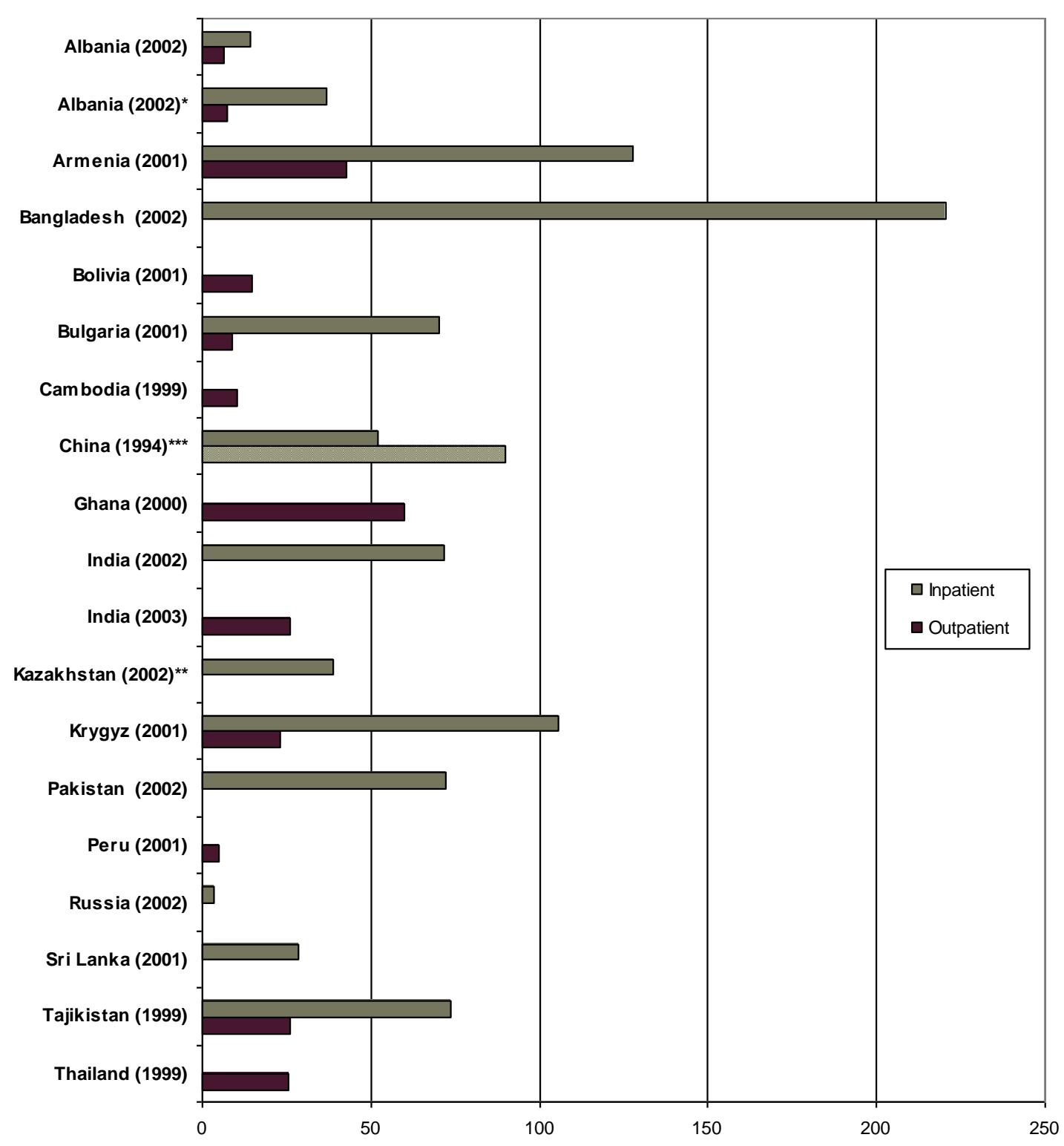


income for health care while the wealthiest households spent the equivalent of half their monthly income reflecting the lack of exemptions for the poor. ${ }^{30}$

These studies point up the salient characteristics of informal payment, but work in this area is just beginning. A better understanding of the phenomenon and how to stem its spread is critical to good governance and accessible health care. The key issues have been outlined and we now turn to policy responses. Though the evidence base is thin, there are good examples of things that can be done and extrapolations from related challenges that can inform policy.

\section{Policy Responses to Informal Payments}

While the extent and size of informal payments are becoming more apparent they have flourished unacknowledged for a long time. Even where some action has been taken the responses have differed and few have been evaluated to determine the relative effectiveness of different interventions.

Health care in most of the developing and transition countries suffers from poor governance and the absence of accountability in public service delivery. Informal payments are an outgrowth of this breakdown as they are accompanied by irregular fiduciary oversight, lack of management, limited oversight of performance, and few if any penalties for illegal or improper behavior. Informal payments ensure that providers are paid for services delivered and that some services actually reach patients, but only for those who can pay, undermining equity principles of publicly financed health care. The absenteeism of public health providers observed in much of the world is rare in transition economies where informal payments have become the major source of health care financing and providers cannot afford to be absent. ${ }^{31}$ However, the two often exist in parallel in other parts of the world.

Addressing informal payments is complex and simply addressing specific abuses is insufficient as the issues are often more systemic in nature. In many contexts the environment more generally needs to be considered. The informal payments issue is addressed first here, followed by discussion of some of the more generic reforms that offer solutions to the underlying problems that give rise to informal payments.

Controlling Informal Payments. Strategies to control informal payments are few. Raising official fees as a substitute for under-the-table payments showed positive effects on patient payment and utilization in pilot programs in Kyrgyz Republic and Cambodia. Both programs made the financial arrangements more equitable, shifted the issue from one of corruption to equity management and, probably most importantly, it ensured that health provider earnings would remain the same.

In Kyrgyz Republic an experiment in two regions introduced formal fees and resulted in a sharp reduction in informal charges. Both multivariate analysis and administrative data showed the proportion of patients making direct payments to providers declining from 60 
percent to 38 percent in the experimental regions while informal payments for the rest of the country rose to 70 percent. In-kind spending by patients for food and linens in the pilot regions with formal fees declined by over 50 percent though there was no change in similar spending in the rest of the country. Formal fees combined with modest insurance payments helped to make health care more affordable and quelled under-the-table payments. $^{32}$

In a major referral hospital in Cambodia reorganization of hospital staffing combined with a transparent official fee policy, clearly designated exemptions, and retained fee revenue that supplemented physician salaries at levels comparable to those earned under the informal arrangements led to more reliable pricing, stable revenue and higher demand. Focus groups identified informal payments as a deterrent to health service use, and the subsequent predictability and equity adjustments improved access without compromising utilization or hospital revenue, the latter a critical component of compensation given salary levels. ${ }^{33}$ Two instances do not allow sweeping conclusions nor was either initiative undertaken in isolation, but the fact that substituting legal for illegal payments and allowing the points of service to retain revenues proved effective and suggests that it is a strategy worth pursuing further

Addressing some of the incentives underlying informal payments provides other options for reform. Some alternative policies include: better incentives for health providers, enhancing accountability for performance, and providing community oversight.

Adequate incentives for health professionals. Providing appropriate incentives for health providers lie more in addressing the structure of the health care system and its financing rather than in limited actions that fix specific problems. Adjustments to pay and benefits, clear criteria for hiring and promotion, defined discipline for misconduct and adequate training to equip workers with needed skills foster a functioning health system. How providers are paid has dramatic effects on performance, as evidence from the OECD countries attests. Payment methods are the cornerstone of incentives for productivity and performance and increasingly developed countries have sought alternatives or at least complementary means to reward performance and productivity.

In most developing countries physician compensation remains salary based. A review of the limited literature on the effect of salary earnings on physician clinical behavior across the OECD concluded that physicians whose earnings are based on salary rather than feefor-service, bonus payments or capitation showed lower productivity, lower levels of care and higher wound rates from surgery. However, salaried doctors facilitated cost control, a major concern in OECD health systems. ${ }^{34}$

Low wages represent one area of potential temptation for corruption. Where earnings are low individuals have second and third jobs, but they also perceive that low wages entitle them to demand contributions from patients. Civil service reform is often required to address egregious structural problems related to postings, promotion and pay, but the health sector could serve as a pilot to launch improvements that stimulate better performance. Evidence from a number of countries, however, suggests that higher pay 
will not necessarily address corruption by itself, but paying wages that are appropriate to existing labor market conditions, prohibiting informal side payments and holding providers accountable could together encourage more transparent and fair transactions, and offer incentives for better provider performance. Although it is expensive for countries to raise wages in public health care services, a reform that regularizes and improves pay has the potential to raise productivity. Higher productivity, in turn, would make it possible to provide at least the same level of services, with fewer workers, thereby offsetting some of the expected increase in the total wage bill. In addition, greater transparency in all fiduciary functions would improve fairness and bolster effectiveness. Alternatively experimentation with other payment arrangements may prove effective. ${ }^{35}$

Enhanced Accountability. Improving accountability of public workers plays a key role in improving governance and relinquishing reliance on informal payments. How that is accomplished is far from straightforward, and evidence on how to accomplish improved accountability remains limited. For example, in Bolivia corruption and informal payments were lower where management was stronger and some form of oversight of staff existed, in this case, frequent written evaluations of performance, a key input for rewarding and disciplining staff. ${ }^{36}$ While a basic management tool, such assessments can have an impact on performance and corruption and are often absent in the worst performing health care systems.

A recent rigorous experiment in Tanzania assessed the importance of training and incentives in determining physician performance across a sample of public and private providers. ${ }^{37}$ The study concludes that while ability is important, institutional incentives, particularly the ability to hire and fire staff, are far more powerful than education or experience in explaining the quality of care provided patients, offering an empirical basis for the priority of putting in place incentives to foster improvements in health care. This obviously poses serious problems for many public programs that rely on public servants to delivery health care, but it makes clear the need to hold providers accountable if abuse is to be curtailed.

Community Oversight. The nature of accountability and how to structure incentives is not apparent from available evidence. In rural or isolated areas community oversight offers an option, though there are few good examples of countries with effective oversight and accountability. Evidence for Bolivia, Madagascar, the Philippines and Uganda suggests that centralized hiring, promotion and deployment of public health workers effectively neutralizes the role of local supervision. If the consequences of absenteeism, taking of bribes and stealing of drugs are beyond the authority of local boards or community oversight bodies then those institutions may bring the community together but they will have no influence over centrally managed health staffs, or their service delivery responsiveness and productivity.

Even where local oversight arrangements exist to promote accountability it does not necessarily mean that they are effective. In Jigawa state in Nigeria hospital management committees meant to oversee and advise hospital managers rarely met, were unclear on their responsibilities, and had little involvement with strategic planning, targeting or 
budget control. ${ }^{38}$ In Madagascar, the fact that local committees were powerless beyond moral suasion led providers to ignore their hollow authority and instead respond to supervisors who had a say in their destiny. ${ }^{39}$ To be effective community leaders need authority, and at the same time they need to be accountable to the local citizenry or to a higher level of government.

Local control where it goes beyond simply oversight holds promise. Under the "Bamako Initiative" that gave communities in selected African countries control over health facilities in exchange for sharing the financing burden showed impressive health status improvements in at least three countries. ${ }^{40}$ In Ceara, Brazil the state instituted a health worker outreach program with contracted workers supervised by the municipalities they served. Local control led to better health in the communities covered by the new state program. ${ }^{41}$ In Bolivia corruption was lower where local organizing groups were active. ${ }^{42}$ In contrast local control proved ineffective in Nigeria, Madagascar and Uganda leaving the issue unresolved, but more experimentation and systematic evaluations can help address this. ${ }^{43}$

\section{Conclusion}

Informal payments are much more widespread than commonly thought. Donors and governments have urged banning user charges in the interests of equity in access to health services. Sweeping removal of a reliable source of revenue from legitimate fees for equity reasons means that both the poor and the well off are subsidized. The more serious issue is that under-the-table payments replace legal charges. The one strategy that holds promise is the introduction of formal fees that allows payment to be above-thetable, but this reflects only preliminary evidence. More fundamental is a shift toward better governance in health care delivery with clear lines of accountability.

While there is some suggestion from Kyrgyz Republic and Cambodia that instituting formal fees can serve to curtail informal payments, the impact of removing fees has not been broadly assessed. Existing evidence suggests that addressing informal payments alone may not be effective. Given the worldwide prevalence of informal payments and their strong negative effects on both equity and good governance policymakers need to focus on the issue and the means to discourage such practices. Private health care and private pay go hand-in-hand, but a private system is inappropriate within the confines of public health care. Not taking heed risks sending signals that irregular financial transactions are acceptable, which compromises the overall public health system if not the government more generally.

\footnotetext{
${ }^{1}$ P. Musgrove, "Public and Private Roles in Health." In Musgrove (ed.) Health Economics in Development. (Washington D.C.: World Bank, 2004).

${ }^{2}$ M. Lewis, "Governance and Corruption in Public Health Care Systems.” Working Paper No. 78. (Washington D.C.: Center for Global Development, 2005).

${ }^{3}$ M. Lewis, "Who Is Paying for Health Care in Europe and Central Asia?" Europe and Central Asia Region. Monograph (Washington D.C.: World Bank, 2000) and M.Lewis, "Informal Health Payments in Central and Eastern Europe and the Former Soviet Union: Issues, Trends and Policy Implications" in Funding Health Care: Options for Europe. Figueres and Moussiales. Editors (Buckingham: Open
} 
University Press, 2002) and T. Ensor, "Informal Payments for Health Care in Transition Economies" in W. Jack and M. Lewis guest editors Social Science and Medicine, Special Issue 58, no. 2 (January 2004): 237246.

${ }^{4}$ P. Bardhan, "Corruption and Development: A Review of Issues." Journal of Economic Literature 35 no. 3: $1310-1346$.

${ }_{6}^{5}$ M. Lewis, "Governance and Corruption in Public Health Care Systems."

${ }^{6}$ J. Falkingham, "Health, health seeking behavior and out of pocket expenditures in Kyrgyzstan 2001". Kyrgyz Household Health Finance Survey. (London School of Economics. Monograph. 2002).

${ }^{7}$ R. Gatti et al., "Determinants of Corruption in Local Health Care Provision: Evidence from 108 Municipalities in Bolivia." (Washington D.C.: World Bank, 2003). DEC Draft Paper.

${ }^{8}$ B. McPake et al., "Informal Economic Activities of Public Health Workers in Uganda: Implications for Quality and Accessibility of Care." Social Science and Medicine. 49, no. (1999): 849-865, and M.

Lindelow et al., "Expenditure Tracking and Service Delivery Survey", The Health Sector in

Mozambique". Final Report. (Washington D.C.: World Bank, 2004), and M. Lindelow et al., "Synthesis of Focus Group Discussions with Health Workers in Ethiopia." (Washington D.C.: World Bank, 2003) or Draft paper.

${ }^{9}$ A sense of the range of data can be seen from the exit surveys. The Bolivia survey collected data from 2888 women in 106 municipalities; the Moldova survey consisted of 390 interviews with physicians, nurses and patients in the capital, Chisinau, and two provinces; the Albanian household survey surveyed 3 provinces; the Poland survey was only of Gdansk and Wroclaw cities; and, the Kazakh hospital survey interviewed 1508 discharged patients from three Almaty City hospitals.

${ }^{10}$ P. Belli, "Formal and Informal Household Spending on Health: A Multi-country Study in Central and Eastern Europe." Harvard School of Public Health, International Health Systems Group. Mimeo. (2002).

${ }^{11}$ G. Gray-Molina et al., "Does Voice Matter? Participation and Controlling Corruption in Bolivian Hospitals," In Diagnosis Corruption Fraud in Latin America's Public Hospitals W. Savedoff and R. Di Tella eds. (2001) and S. Chakraborty et al., "When is "Free" Not So Free? Informal Payments for Basic Health Services in Bolivia." Mimeo. DEC Draft Paper (2002).

${ }^{12}$ G.K. Thampi, Corruption in South Asia, Insights \& Benchmarks from Citizen Feedback Surveys in Five Countries.Transperency International Monograph. (2002).

${ }^{13}$ K. Gopakumar, "Citizen Feedback Surveys to Highlight Corruption in Public Services: the Experience of Public Affairs Centre, Bangalore." Mimeo. (September 1998).

${ }^{14}$ World Bank, "Albania: Poverty Assessment". Europe and Central Asia Region.” (Washington D.C.: World Bank, 2003).

${ }^{15}$ H. Shahriari et al., "Institutional Issues in Informal Health Payments in Poland: Report on the Qualitative Part of the Study". HNP Working Paper. (Washington D.C.: World Bank, 2001).

${ }^{16}$ G. Bloom et al., "How Health Workers Earn a Living in China" Human Resources for Health

Development Journal 5, no. 1, (2001): 25-38. and Belli, et al., "Institutional Issues in Informal Health Payments in Poland", and Lindelow et al., "Synthesis of Focus Group Discussions", and J. Kutzin et al., "Formalizing Informal Payments in Kyrgyz Hospitals: Evidence from Phased Implementation of Financing Reforms." (Paper presented at IHEA Conference, San Francisco, California. 2003).

${ }^{17}$ Lindelow et al., "Synthesis of Focus Group Discussions"

${ }^{18}$ T. Vian et al, "Informal Payments in Government Health Facilities in Albania: Results of a Qualitative Study". Social Science and Medicine 62, no. 10 (2005): 877-887. P. Belli et al., "Out of pocket and Informal Payments in the Health Sector: Evidence from Georgia". Health Policy, 70 (2004): 109-23; and Belli, et al., "Institutional Issues in Informal Health Payments in Poland."

${ }^{19}$ Belli et al., "Out of Pocket and Informal Payments in the Health Sector," and Narayan, D., Voices of the Poor. (World Bank and Oxford University Press. Washington, D.C.: 2000), and J. Killingsworth et al., "Unofficial Fees in Bangladesh: Price, Equity and Institutional Issues." Health Policy and Planning, 14 no. 2, (1999): 152-163.

${ }^{20}$ R. Thompson, "Informal Payments for Emergency Hospital Care in Kazakhstan: An Exploration of Patient and Physician Behavior." Ph.D. thesis. (UK: University of York, 2004).

${ }^{21}$ M. Lewis, "Who Is Paying for Health Care in Europe and Central Asia?" and Lewis "Informal Health Payments in Central and Eastern Europe" and Falkingham "Health, health seeking behavior" and J. 
Falkingham "Poverty, Out-of-Pocket Payments and Access to Health Care: Evidence from Tajikistan," and J. Killingsworth et al., "Unofficial Fees in Bangladesh."

${ }^{22}$ Bloom et al., "How Health Workers Earn a Living in China."

${ }^{23}$ D.P. Hotchkiss, et al., "Out-of-pocket Payments and Utilization of Health Care Services in Albania:

Evidence from Three Districts" PHR Plus Report, August (2005).

${ }^{24}$ World Bank, "Albania: Poverty Assessment".

${ }^{25}$ P. Musgrove, "Public and Private Roles in Health."

${ }^{26}$ J. Killingsworth et al., "Unofficial Fees in Bangladesh."

${ }^{27}$ A. Banerjee et al., "Wealth, Health and Health Services in Rural Rajasthan." American Economic Review Papers and Proceedings. 94, no. 2 (2004): 326-330.

${ }^{28}$ B. McPake et al., "Informal Economic Activities of Public Health Workers in Uganda: Implications for Quality and Accessibility of Care."

${ }^{29}$ J. Falkingham, "Health, health seeking behavior."

${ }^{30}$ A. Sari et al., "Affording Out-of-Pocket Payments for Health Care Services: Evidence from Kazakhstan." Eurohealth 6, no. 2 (Spring). (2000).

${ }^{31}$ M. Lewis, "Governance and Corruption in Public Health Care Systems."

${ }^{32}$ J. Kutzin et al., "Formalizing Informal Payments in Kyrgyz Hospitals."

${ }^{33}$ S. Barber et al., "Formalizing Under-the-Table Payment to Control Out-of-Pocket Hospital Expenditures in Cambodia" Health Policy and Planning 19, no. 40 (2004): 199-208.

${ }^{34}$ T. Gosden et al., "How Should We Pay Doctors? A Systematic Review of Salary Payments and their Effect on Doctor Behavior." Quarterly Journal of Medicine 92 (1999): 47-55.

${ }^{35}$ M. Lewis, "Governance and Corruption in Public Health Care Systems."

R. Gatti et al., "Determinants of Corruption in Local Health Care Provision."

${ }^{37}$ K. Leonard, "Getting Clinicians To Do Their Best: Ability, Altruism and Incentives." University of Maryland. Mimeo (Draft) (2005).

${ }^{38}$ World Bank, "Nigeria: Health, Nutrition and Population: Country Status Report." (Washington D.C.: World Bank, 2006).

${ }^{39}$ D. Brinkerhoff, "Pro-poor Health Services in Madagascar: Decentralization and Accountability". Paper presented at Global Health Council Annual Conference, Washington D.C. (May-June, 2005).

${ }^{40} \mathrm{~V}$. Ridde et al., "Improve the accessibility of essential drugs for the populations of one medical region in Burkina Faso" Sante 15, no. 3 (2005): 175-82; A. Soucat et al., "Local cost sharing in Bamako Initiative systems in Benin and guinea: assuring the financial viability of primary health care." International Journal of Health Planning and Management, June 12, Supplement 1 (1997): S109-35.

${ }^{41}$ J. Tendler, and S. Freedheim, "Trust in a Rent-Seeking World: Health and Government Transformed in Northeast Brazil." World Development 22, no. 12 (1994): 1771-1791.

${ }^{42}$ R. Gatti et al., "Determinants of Corruption in Local Health Care Provision."

${ }^{43}$ World Bank, "Nigeria: Health, Nutrition and Population." McPake et al., "Informal Economic Activities of Public Health Workers in Uganda." Brinkerhoff, "Pro-poor Health Services in Madagascar." 


\begin{tabular}{|c|c|c|}
\hline \multicolumn{3}{|c|}{ Appendix I: Data Sources } \\
\hline Country & Data Year & Source \\
\hline Albania & 2002 & USAID Regional Corruption Monitoring Report \\
\hline Albania & 2002 & World Bank LSMS \\
\hline Armenia & 2001 & World Bank LSMS \\
\hline Bangladesh & 2002 & Transparency International, 2002 \\
\hline Bolivia & 2001 & World Bank Municipal Survey of Corruption \\
\hline Bosnia & 2000 & Corruption Diagnostic Survey \\
\hline Bosnia & 2002 & USAID Regional Corruption Monitoring Report \\
\hline Bulgaria & 2001 & World Bank LSMS \\
\hline Bulgaria & 2002 & USAID Regional Corruption Monitoring Report \\
\hline Cambodia & 1999 & World Bank Governance and Corruption \\
\hline China & n.d. & Bloom, Han and Li, 2001 \\
\hline Colombia & n.d. & National Corruption Survey \\
\hline Croatia & 2002 & USAID Regional Corruption Monitoring Report \\
\hline Czech Republic & 2002 & Horthava, 2002 \\
\hline Georgia & 2000 & World Bank LSMS \\
\hline Ghana & 1998 & World Bank LSMS \\
\hline Ghana & 2000 & Ghana/World Bank Governance and Corruption Survey \\
\hline Hungary & 2002 & Gaal, 2002 \\
\hline India & 2002 & Transparency International, 2002 \\
\hline Indonesia & 2001 & $\begin{array}{l}\text { Indonesia Partnership for Governance Reform/World Bank } \\
\text { Corruption Diagnosis Survey }\end{array}$ \\
\hline Kazakhstan & 2001 & World Bank Institutional and Governance Review \\
\hline Kosovo & 2000 & World Bank LSMS \\
\hline Kyrgyz & 2001 & World Bank LSMS \\
\hline Kyrgyz & 2001 & World Bank LSMS \\
\hline Latvia & 1998 & World Bank Corruption Diagnostic Survey \\
\hline Macedonia & 2002 & USAID Regional Corruption Monitoring Report \\
\hline Madagascar & 2001 & Transparency International Report \\
\hline Moldova & 2000 & Transparency International Report, 2001 \\
\hline Moldova & 2002 & WHO/IDB/Transparency International Report \\
\hline Morocco & 2001 & Transparency International \\
\hline Nepal & 2002 & Transparency International \\
\hline Pakistan & 2002 & Transparency International \\
\hline Paraguay & 1999 & World Bank Corruption Diagnostic Survey \\
\hline Peru & 2001 & World Bank Qualitative Survey \\
\hline Poland & 1998 & Chawla, Berman \& Kawiorska, 2001, Survey \\
\hline Romania & 2000 & World Bank Corruption Diagnostic Survey \\
\hline Romania & 2002 & FBS \\
\hline Russia & 2002 & Russian Household Survey \\
\hline Senegal & 2001 & Transparency International Report \\
\hline Serbia & 2002 & USAID Regional Corruption Monitoring Report \\
\hline Slovakia & 2000 & World Bank Corruption Diagnostic Survey \\
\hline Sri Lanka & 2001 & Transparency International Report \\
\hline Tajikistan & 1999 & World Bank LSMS \\
\hline Tajikistan & 2001 & Transparency International Report \\
\hline Thailand & 1999 & Thailand/World Bank Corruption Diagnostic Survey \\
\hline Vietnam & 1998 & World Bank LSMS \\
\hline Uzbekistan & 2001 & FBS \\
\hline
\end{tabular}


